\title{
Laboratory measurements of the optical properties of sea salt aerosol
}

\author{
R. Irshad ${ }^{1}$, R. G. Grainger ${ }^{1}$, D. M. Peters ${ }^{1}$, R. A. McPheat ${ }^{2}$, K. M. Smith ${ }^{2}$, and G. Thomas ${ }^{1}$ \\ ${ }^{1}$ Atmospheric, Oceanic and Planetary Physics, Clarendon Laboratory, University of Oxford, UK \\ ${ }^{2}$ Space Science and Technology Department, Rutherford Appleton Laboratory, Didcot, UK
}

Received: 24 August 2007 - Published in Atmos. Chem. Phys. Discuss.: 4 January 2008

Revised: 1 December 2008 - Accepted: 1 December 2008 - Published: 13 January 2009

\begin{abstract}
The extinction spectra of laboratory generated sea salt aerosols have been measured from $1 \mu \mathrm{m}$ to $20 \mu \mathrm{m}$ using a Bruker 66v/S FTIR spectrometer. Concomitant measurements include temperature, pressure, relative humidity and the aerosol size distribution. The refractive indices of the sea salt aerosol have been determined using a simple harmonic oscillator band model (Thomas et al., 2004) for aerosol with relative humidities at eight different values between $0.4 \%$ to $86 \%$. The resulting refractive index spectra show significant discrepancies when compared to existing sea salt refractive indices calculated using volume mixing rules (Shettle and Fenn, 1979). Specifically, an additional band is found in the refractive indices of dry sea salt aerosol and the new data shows increased values of refractive index at almost all wavelengths. This implies that the volume mixing rules, currently used to calculate the refractive indices of wet sea salt aerosols, are inadequate. Furthermore, the existing data for the real and imaginary parts of the refractive indices of dry sea salt aerosol are found not to display the Kramers-Kronig relationship. This implies that the original data used for the volume mixing calculations is also inaccurate.
\end{abstract}

\section{Introduction}

Atmospheric aerosols cause direct and indirect forcing of the atmosphere's radiation budget. Aerosol particles may act as cloud condensation nuclei and affect the lifetime of clouds (Penner et al., 2001; Lohmann and Feichter, 2005) or they can influence radiative transfer by scattering and absorbing solar radiation (IPCC, 2007). The optical properties

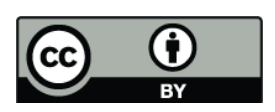

Correspondence to: R. Irshad (rirshad@atm.ox.ac.uk) of aerosols are particularly important as they are required to perform radiative transfer calculations in global climate models and allow the radiative effect of such aerosols to be estimated (Hess et al., 1998; Dobbie et al., 2003). In fact the need for refined optical aerosol models for improving satellite retrieval algorithms has been identified by many authors (Torres et al., 1998; King et al., 1999; Dubovik et al., 2002).

Marine aerosols provide a significant contribution to the aerosol environment due to the large source area of the oceans, which cover approximately $70 \%$ of the Earth's surface. Sea salt aerosol (SSA) is a component of marine aerosol made up of seawater and dry sea salt particles, and is produced by any mechanism releasing spray from the sea surface. As well as acting as cloud condensation nuclei (Twomey and McMaster, 1955) SSA can also act as a sink for condensable gases, affecting the deposition rate of nitrogen in the form of ammonia to the ocean and thus possibly inhibiting the formation of other aerosol particles (Savoie and Prospero, 1982). Coarse SSA particles cause corrosion and are a main contributor to ocean-atmosphere fluxes of organic substances, electric charge, micro-organisms etc. SSA also plays a part in the atmospheric cycles of chlorine and other halogens (Finlayson-Pitts and Hemminger, 2000). Finally, recent observations suggest that the majority of accumulation mode aerosols in the marine boundary layer $(0.1 \mu \mathrm{m}<$ Radius $<1 \mu \mathrm{m})$ contain sea salt, and that this sea salt aerosol is responsible for the majority of aerosolscattered light (Murphy et al., 1998).

For the lowest tens of metres above the ocean, SSA particles usually exist in liquid form. Above this height, at relative humidities (RH) between $45 \%$ and $75 \%$, SSA particles may be in either liquid droplet or dry salt form depending on the relative humidity of the particle on creation. As SSA particles are usually formed as liquid droplets, and the RH

Published by Copernicus Publications on behalf of the European Geosciences Union. 
Table 1. Chemical composition of Maldon sea salt. Calcium carbonate precipitates first upon evaporation and this is removed before the salt is harvested. This may explain the high $\mathrm{NaCl}$ content of the salt.

\begin{tabular}{lc}
\hline Chemical compound & Percentage $(\%)$ \\
\hline sodium chloride & 98.501 \\
potassium chloride & 0.018 \\
magnesium sulphate & 0.100 \\
calcium sulphate & 0.548 \\
water & 0.798 \\
insoluble residue & 0.035 \\
\hline
\end{tabular}

rarely drops to below $45 \%$, it may be assumed that they always exist as liquid solution drops in the atmosphere (Lewis and Schwartz, 2004). Studies by Cziczo et al. (1997) also confirm that sea salt aerosols may exist in liquid form down to quite low $\mathrm{RH}$ values.

The refractive indices of sea salt have previously been obtained using reflectance and transmittance measurements made on bulk samples (Volz, 1972). These were made using pellets of $\mathrm{KBr}$ with a layer of powdered sea salt pressed onto the surface, and not using actual aerosol. The origin and composition of the sea salt used are not given. There is also some ambiguity as to whether or not the pellets remained dry during measurement. The current refractive index data for dry sea salt is based on this Volz (1972) data, after it has been extended up to $50000 \mathrm{~cm}^{-1}(0.2 \mu \mathrm{m})$ by Shettle and Fenn (1979) using data compiled by Dorsey (1940). While additional measurements have been made on bulk solutions of $\mathrm{NaCl}$ (Querry et al., 1976; Yunus, 1992; Weis and Ewing, 1999; Neto et al., 2004), these may not be directly applicable to sea salt aerosol which contains additional compounds other than $\mathrm{NaCl}$. Additionally, Weis and Ewing (1999) made measurements of $\mathrm{NaCl}$ droplets under controlled $\mathrm{RH}$ ranging from 15 to $95 \%$. However, above $44 \%$ RH the aerosol was given insufficient time to reach equilibrium with surroundings. Tang et al. (1997) have made measurements on sea salt solution using the single particle levitation method (Tang and Munkelwitz, 1991). However the solution used was made up of four salts selected to approximate sea salt composition rather than actual sea salt. The particle on which measurements were made was 6-8 $\mu \mathrm{m}$ in diameter when dry, meaning that when the RH was increased the particle was significantly larger than accumulation mode aerosol and therefore not necessarily representative of atmospheric SSA. Additionally both the single particle levitation method and the methods employed by Yunus (1992) and Neto et al. (2004) involve measurements made at a single wavelength rather than over a range of wavelengths. A parameterisation of the extinction coefficient, single scattering co-albedo and asymmetry parameter has been undertaken by Li et al. (2008) over a limited RH range. However, these are derived using refrac- tive indices from Volz (1972) and Shettle and Fenn (1979). Therefore the scope for more accurate measurements of SSA over a range of wavelengths remains.

Currently, the refractive indices of wet SSA are calculated using mixing rules, i.e. taking a weighted average of the refractive indices of water and dry sea salt (Shettle and Fenn, 1979). While this method may be valid for solid particles suspended in water, it may not hold for solutions of salts such as sodium chloride, which readily dissolve in water. The salts dissociate into separate ions when dissolved in water, for example, sodium chloride dissociates to $\mathrm{Na}^{+}$and $\mathrm{Cl}^{-}$ ions. This means that the values of refractive index of sea salt used in current climate and retrieval models may not be physically realistic. For example, Winter and Chylek (1997) use SSA refractive index data from Shettle and Fenn (1979) to calculate the planetary clear sky albedo. However, the values they obtain for optical depth are slightly lower than measured values, and no verification of the mixing rules is undertaken. This suggests that there remains a pressing need for measurements of the optical properties of SSA to quantify and improve on the accuracy of those currently in use.

Previous methods of determining optical properties of aerosol substances include aerosol extinction spectroscopy from small particles and thin films. Refractive index is then calculated from extinction measurements using a KramersKronig method that has been described extensively in literature (Milham et al., 1981; Clapp et al., 1995). In this case thin film techniques were rejected due to the possibility of heterogeneous nucleation and interaction with a substrate.

Transmittance measurements were undertaken at $298 \mathrm{~K}$ using Fourier-transform-infra-red (FTIR) spectroscopy and the resulting spectra were converted to complex refractive indices over a range of wavelengths using a classical damped harmonic oscillator (CDHO) model, to fit the shape of absorption bands, combined with a Mie scattering algorithm (Thomas et al., 2004). The resulting refractive index spectra are presented in this paper and, where possible, compared with current data from HITRAN (Rothman, 2005).

\section{Methodology}

Sea salt crystals were dissolved in analytical reagent grade water to make a salt solution. Maldon sea salt was used: this is obtained by evaporation of seawater collected from the east coast of England. The chemical composition of this sea salt, obtained from the manufacturer, is given in Table 1. As the ratio of the major constituents of sea water are thought to vary minimally with geographical location (Culkin, 1965; Wilson, 1975; DOE, 1994; Lewis and Schwartz, 2004), these salt crystals may be considered to approximate the sea salt in the atmosphere. However, it should be noted that limesscale precipitates first during the evaporation process, and is removed before the remaining compounds are harvested as the manufacturers do not consider this to be a part of sea salt. 
While this would affect the spectra in the near-infrared, it should not have a significant effect over the range investigated for this study. Seawater samples were not used due to likely presence of contaminants that would be evident in the spectral measurements, as well as the low concentration of salt in the water which would result in poor yields of sea salt.

The salt solution was aerosolised using an OMRON NEU17 ultrasonic nebuliser. The aerosol was transported in a buffer flow of nitrogen gas and dried using diffusion dryers (Blackford and Simons, 1986). The dry aerosol was then carried into a 2 litre glass conditioning vessel where the RH of the aerosol was varied by the introduction of water vapour from a heated water bath. The conditioner was of a sufficient volume to allow the aerosol particles to grow to a stable size before entering the aerosol cell. This is a double-walled stainless steel cell with length $25 \mathrm{~cm}$ and internal volume approximately $145 \mathrm{~cm}^{3}$.

The aerosol cell was mounted horizontally in an evacuated chamber attached to a Bruker 66V/S Fourier transform spectrometer. Here, intensity measurements were made over a range of wavenumbers. A Honeywell RH and temperature sensor was mounted at the entrance of the cell to measure the exact RH of the aerosol within the cell. The cell temperature remained at approximately $298 \mathrm{~K}( \pm 2 \mathrm{~K})$ throughout the experiment. Particle size and number density measurements were also made using a GRIMM Sequential Mobility Particle Sizer plus Counter (SMPS+C) and an API Aerosizer instrument (an aerodynamic particle sizer).

Background spectra were recorded to account for the spectral response of the Fourier transform spectrometer and any artefacts introduced by the windows of the optical cell. A Kalman smoother (Kalman, 1960; Maybeck, 1979) was used to match an appropriate background spectrum to each aerosol measurement, and the transmission spectra were calculated using the following equation:

$T_{c}(v)=\frac{I(v)}{I_{0}(v)}$

where $I_{0}(v)$ is the background intensity, $I(v)$ is the sample intensity and $T_{c}(v)$ is the transmission.

Transmission measurements of sea salt aerosol were obtained from 500 to $8000 \mathrm{~cm}^{-1}$ at a number of different $\mathrm{RH}$ values. These are given in Table 2 alongside estimated molality values. Several spectral measurements were taken at each RH value and averaged to obtain the final transmission spectrum. The error on these final spectra was estimated by calculating the variance of each spectral point in time from the original averaged data. The transmission data was then processed to retrieve the complex refractive index. The error for each measurement was also updated during the retrieval process to add the uncertainty for each parameter in the model to the measurement error.

Some of the transmission spectra showed evidence of contamination by gas lines of carbon dioxide and water. These were modelled and removed using an iterative non-linear
Table 2. The RH, molality, $M_{500}$, number density, particle size and spread values for the sea salt aerosols produced and measured.

\begin{tabular}{lccccc}
\hline RH $(\%)$ & Molality & $M_{500}$ & $N_{0}\left(\times 10^{6} \mathrm{~cm}^{-3}\right)$ & $R_{m}(\mu \mathrm{m})$ & $S$ \\
\hline 0.4 & 7.697 & 1.557 & 3.806 & 0.355 & 1.379 \\
22.9 & 7.016 & 1.562 & 0.469 & 0.499 & 1.166 \\
29.5 & 6.016 & 1.555 & 0.639 & 0.516 & 1.156 \\
38.5 & 4.827 & 1.530 & 0.756 & 0.543 & 1.142 \\
48.8 & 3.856 & 1.499 & 0.676 & 0.573 & 1.161 \\
74.2 & 2.285 & 1.434 & 0.385 & 0.764 & 1.171 \\
76.7 & 2.074 & 1.425 & 0.543 & 0.756 & 1.239 \\
86.4 & 1.234 & 1.386 & 0.526 & 0.897 & 1.010 \\
\hline
\end{tabular}

least squares fit retrieval (Rodgers, 2000). However, in some of the spectra, particularly at high RH values, there is still evidence of some remaining lines. This leads to increased uncertainty in the areas where water lines are expected for these spectra.

\section{Results}

\subsection{Classical damped harmonic oscillator model}

The final transmission spectrum was used to derive the complex refractive index using a CDHO model after Thomas et al. (2004). In this method, the molecular absorption of aerosol molecules is modelled using a CDHO model that provides a best estimate of the shape of the absorption bands. A Mie scattering algorithm is then used in conjunction with the CDHO model to fully describe the absorption spectrum (Grainger et al., 2004). The final model of the spectrum is fitted to measurements using a numerical optimal estimation algorithm and the complex refractive index is retrieved.

Two iterations of the refractive index retrieval were performed in total. A first order approximation of the refractive index was obtained by using concomitant measurements of size and number density as a priori information for the retrieval. From this, the variation with molality of the refractive index at a fixed point could be derived. At high wavenumbers the real part of the refractive index tends towards a constant value. The refractive index at $20000 \mathrm{~cm}^{-1}(500 \mathrm{~nm})$ was used to represent this value, as this was the highest wavenumber at which measurements were taken. The trend in these $m_{500}$ values was then modelled (Fig. 1) to provide a fixed value to be used in the final refractive index retrieval. Final retrieved parameters are shown in Table 2.

The a priori band set was built up by the inclusion of expected absorption bands from prior knowledge, and the addition and removal of subsequent bands based on a trial and error method. These band sets were later cross-checked with current data on the infrared absorption features of artificial seawater (Cziczo et al., 1997) and the component compounds of SSA in the literature (Cziczo and Abbatt, 2000). Table 3 shows the set of band parameters for $74 \%$ RH sea 


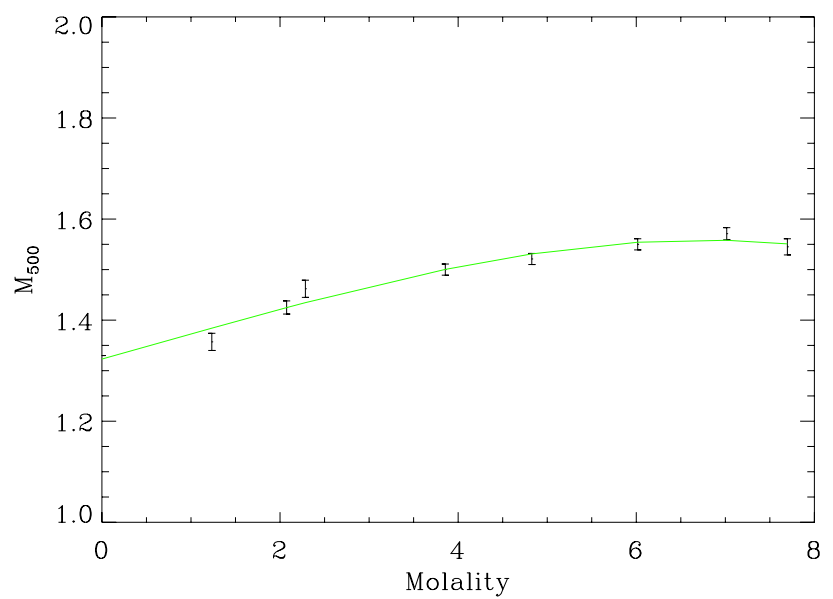

Fig. 1. Variation of refractive index at $500 \mathrm{~nm}$ with molality for sea salt aerosol. The initial point at 0 molality is that of pure water and is included for comparison.

Table 3. Band parameters for $74 \%$ RH sea salt aerosol. The position refers to the wavenumber position of the oscillator centre, the width is the damping constant and the strength gives the maximum intensity of each band described by the CDHO model. Bands due to water are present at $\sim 1650 \mathrm{~cm}^{-1}$ and $\sim 3430 \mathrm{~cm}^{-1}$.

\begin{tabular}{lcc}
\hline Position $\left(\mathrm{cm}^{-1}\right)$ & Width $\left(\mathrm{cm}^{-1}\right)$ & Strength $\left(\mathrm{cm}^{-2}\right)$ \\
\hline 351.5 & 168.4 & 438015 \\
607.7 & 277.9 & 207943 \\
1146.8 & 140.3 & 10706 \\
1447.5 & 376.7 & 70858 \\
1643.4 & 86.4 & 109899 \\
2094.3 & 251.9 & 39014 \\
3470.8 & 152.1 & 1137066 \\
\hline
\end{tabular}

salt aerosol. As the RH of the aerosol increased, the size and width of the parameters corresponding to water bands increased. Similarly, as the RH decreased, the size and width of the water bands decreased until they disappeared for the dry sea salt aerosol.

\subsubsection{Refractive index retrieval}

The retrieval algorithm fits extinction curves calculated from the measured data. Figure 2 shows the extinction calculated from measurements of dry sea salt aerosol compared with the extinction from previous values of dry sea salt refractive indices. The latter data are obtained from the HITRAN database (Rothman, 2005) and are based on measurements taken by Volz (1972), and calculations performed by Shettle and Fenn (1979).

The results of the refractive index retrieval for dry sea salt aerosol are shown in Fig. 3. The results show that the re-

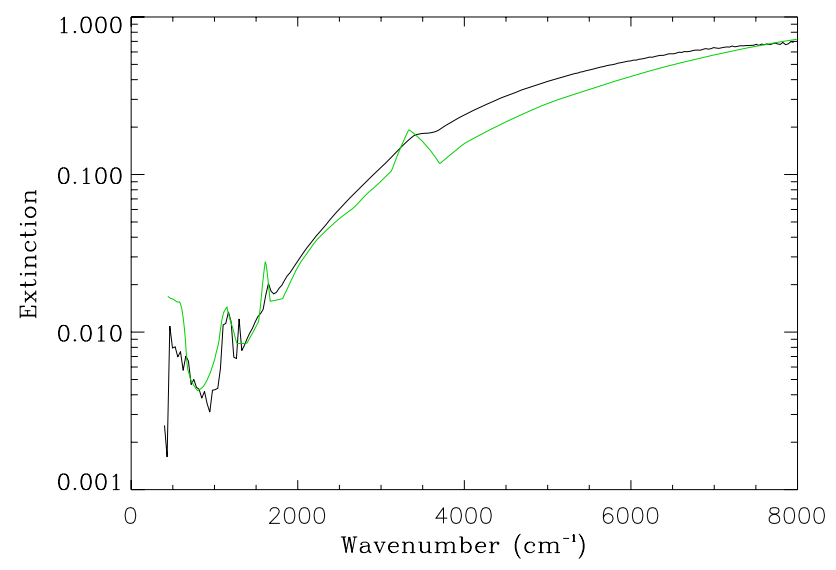

Fig. 2. Sea salt aerosol extinction from current HITRAN data (green) and from new measurements (black). Calculated assuming a particle size of $0.199 \mu \mathrm{m}$ and a particle number density of $9.05 \times 106^{6} \mathrm{~cm}^{-3}$.

trieved values of the imaginary part, $k$, of the refractive index, follow the shape of the HITRAN data but the experimental data reveal an additional peak at $\sim 1330 \mathrm{~cm}^{-1}$. This peak is not present in the HITRAN data, but is present in the FTIR extinction spectra of $\mathrm{NH}_{4} \mathrm{HSO}_{4}$ and $\mathrm{NH}_{4} \mathrm{NO}_{3}$, components of sea salt (Cziczo and Abbatt, 2000). The retrieved spectrum also shows greater detail than the HITRAN data due to a higher resolution. However, the real part of the refractive index, $m$, from the experimental data looks very different to that presented by HITRAN. These data were originally obtained by reflectance measurements (Volz, 1972), rather than from transmittance measurements.

The retrieved refractive index data for sea salt aerosols of approximately $49 \%$ and 86\% RH are shown in Figs. 4 and 5. A clear decrease in the values of the real part of the refractive index at large wavenumbers is observed as the RH increases. Again, the general trend of the variation of refractive index with wavenumber is similar for both data sets in that peaks occur at approximately the same wavenumber values. However, there are significant differences in the size and shapes of these peaks, and the overall magnitude of the real part of the refractive index is consistently greater in the experimental data when compared to the HITRAN data.

\section{Discussion}

\subsection{Comparison with HITRAN data}

There is a clear similarity between the two extinction curves shown in Fig. 2. However, the HITRAN data consist of far fewer points and, possibly as a result of this lower resolution, do not show the peak at $\sim 1330 \mathrm{~cm}^{-1}$ which is evident in the experimental data, and in the infrared extinction spectra 

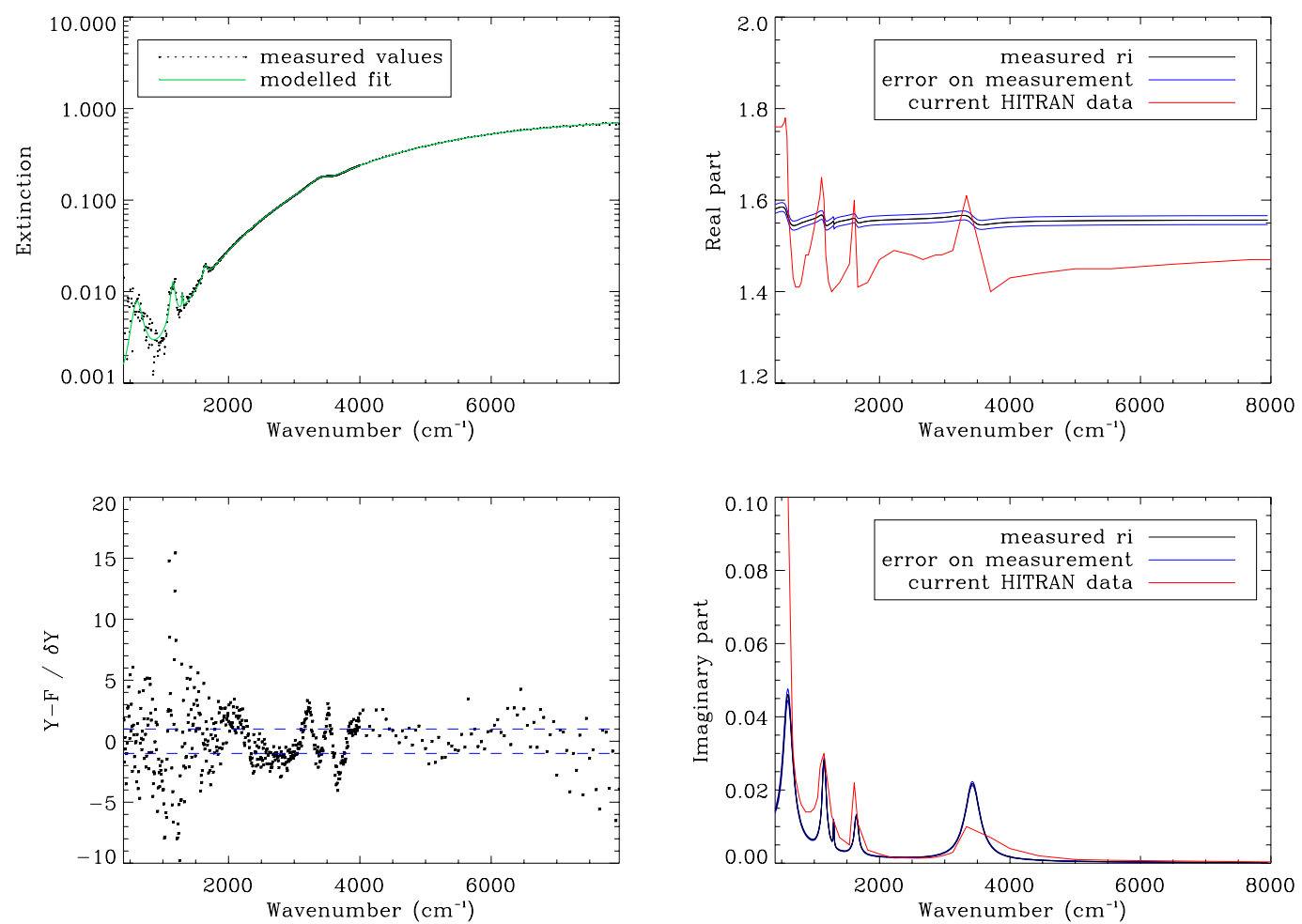

Fig. 3. Refractive index retrieval for dry sea salt aerosol. Variation of extinction with wavenumber is shown in the top left with measured values shown as black points and the modelled fit shown in green. The residual is shown in the plot to the bottom left. The right hand graphs give refractive index data retrieved from measurements in black with the error bounds in blue. Current data from HITRAN are shown in red for comparison.

of $\mathrm{NH}_{4} \mathrm{HSO}_{4}$ and $\mathrm{NH}_{4} \mathrm{NO}_{3}$, components of sea salt (Cziczo and Abbatt, 2000). When plotted at the same resolution and sampling as the HITRAN data, the new data no longer exhibits this additional peak, confirming that the lower resolution of the HITRAN data would have made this peak undetectable. The resolution of the HITRAN data varies over the whole wavenumber range specified. However, the average resolution of this data is approximately $87 \mathrm{~cm}^{-1}$ over the wavenumber range $500-8000 \mathrm{~cm}^{-1}$, whereas the average resolution of our data is $4 \mathrm{~cm}^{-1}$ over the same range. Some spectra were recorded at a higher resolution (approximately $0.2 \mathrm{~cm}^{-1}$ ) but no finer structure was visible due to this higher resolution, other than at those places in the spectra where gas lines were present.

The peaks at $\sim 1625 \mathrm{~cm}^{-1}$ and $\sim 3430 \mathrm{~cm}^{-1}$ are much larger in the HITRAN data. The positions of these peaks correspond to the positions of peaks expected due to water features. This suggests that the sea salt pellets used to make these measurements were not completely dry. Any subsequent calculations made using these values for dry sea salt would therefore also be incorrect. In addition, the extinction curve of the HITRAN data tends towards a much lower value at high wavenumbers than for the experimental data.
To further investigate the discrepancies between the data sets, attempts were made to retrieve band parameters from the refractive index data from HITRAN. It was anticipated that these would provide the basis of a priori information for retrievals from sea salt experimental data. These attempts proved unsuccessful, indicating that the real and imaginary parts of the refractive index data from HITRAN did not correspond according to the equations used to relate these parameters in the CDHO model (Thomas et al., 2004). This implies that the real and imaginary refractive indices presented by Volz (1972) do not display the Kramers-Kronig relationship.

A priori information was then obtained from particle size and number density measurements made during the experiments, and the refractive indices of dry sea salt aerosol were retrieved (Fig. 3). As it had been concluded that the real and imaginary parts of the refractive index data from HITRAN did not correspond, the significant differences between the experimental and HITRAN data for the real part of the refractive index for dry sea salt are unsurprising. The new retrieved real values are relatively constant, although slight disturbances are observed at the wavenumber values where peaks are evident in the HITRAN data. Two of these peaks 

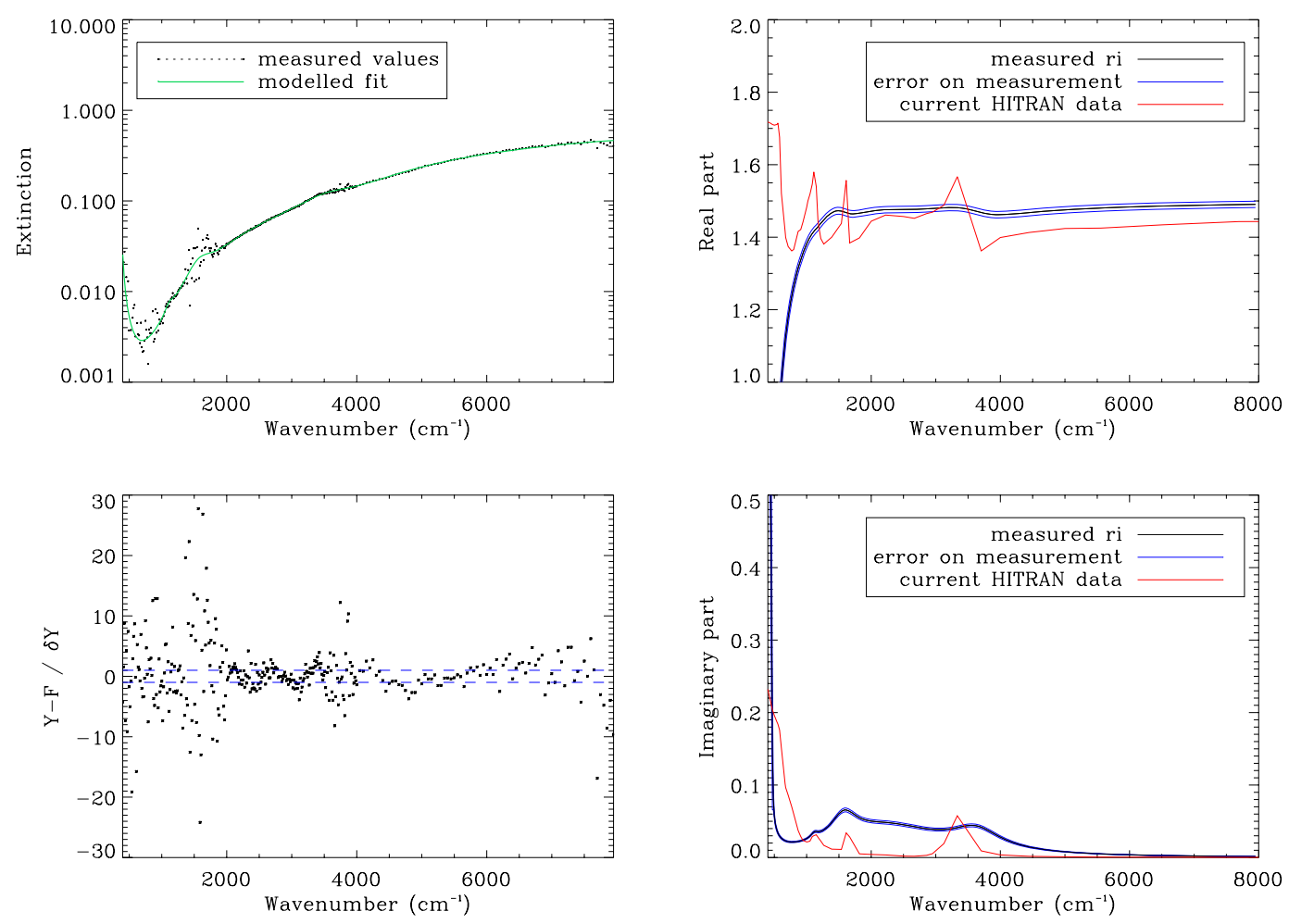

Fig. 4. Refractive index retrieval for $50 \%$ RH sea salt aerosol.
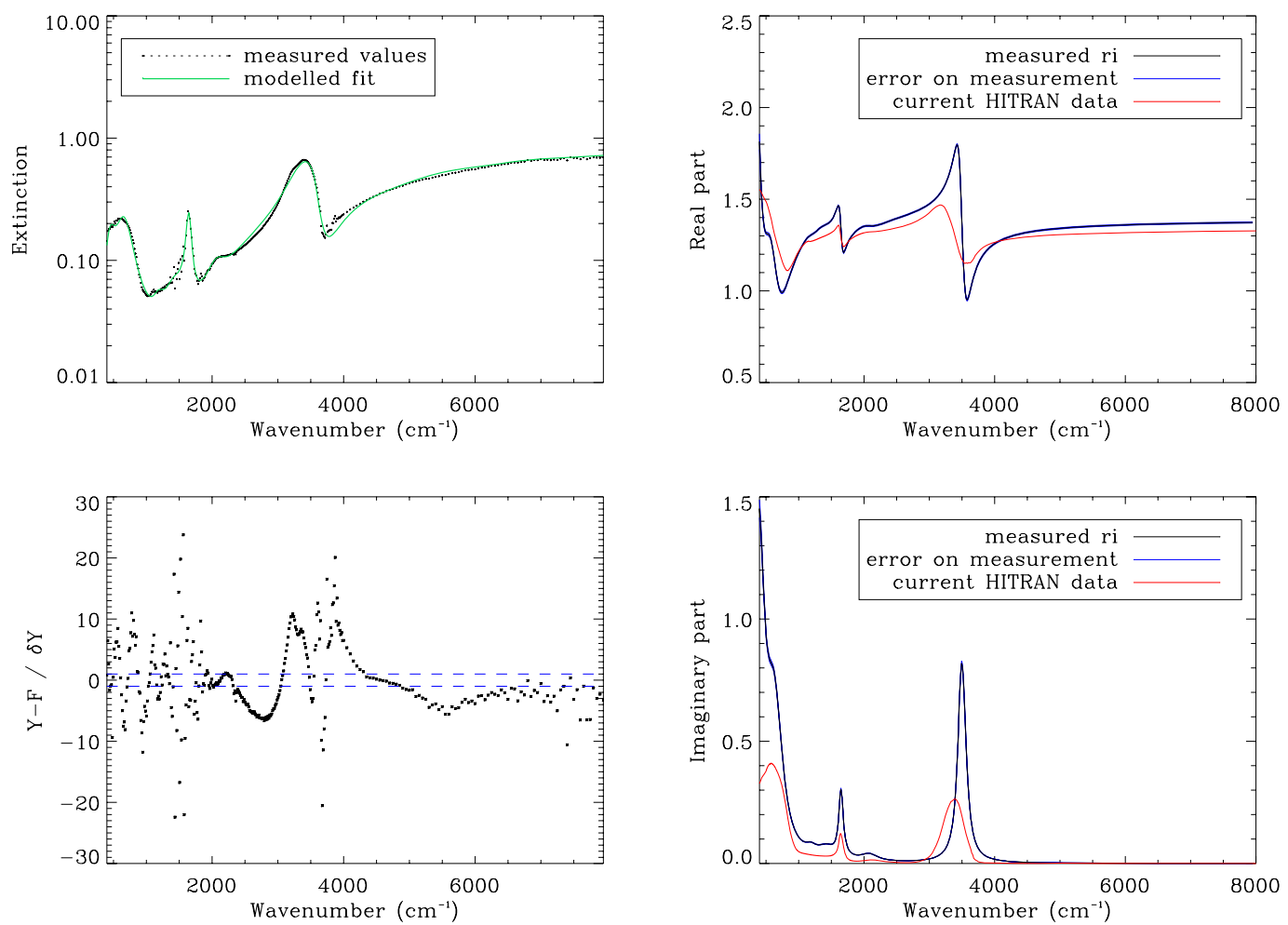

Fig. 5. Refractive index retrieval for $90 \%$ RH sea salt aerosol. 
are expected to be the result of water at $\sim 1625 \mathrm{~cm}^{-1}$ and $\sim 3430 \mathrm{~cm}^{-1}$, and these were evident in the extinction graph (Fig. 2). Once more, there is a feature at $\sim 1330 \mathrm{~cm}^{-1}$ in both the real and imaginary parts of the refractive indices that suggests the presence of a peak undetected by the HITRAN data. The greatest difference between the new data and the current HITRAN data is the increased magnitude of the real part of the new data. A similar increase in magnitude is seen in the imaginary part of the new data. The imaginary parts of both the new and the current HITRAN data tend to zero at $\sim 7000 \mathrm{~cm}^{-1}$.

The measured refractive indices of $49 \%$ and $86 \%$ RH sea salt aerosol are shown in Figs. 4 and 5 respectively for further comparisons with the current data from HITRAN. Once again the magnitude of both parts of the measured refractive indices are greater than the magnitude of the current data, although this difference becomes smaller as the RH increases. At $49 \%$ RH the peaks of the real part of the HITRAN data are greater in amplitude and better defined than those of the new measurements, suggesting a greater level of water than in the aerosol produced for the new measurements. The HITRAN data also show a peak at $\sim 400 \mathrm{~cm}^{-1}$ in the real part of the refractive index that is not present in the new measurements. However, this peak does appear in the new measurements of $86 \% \mathrm{RH}$ sea salt aerosol, suggesting that it is due to a high water content. The new $86 \% \mathrm{RH}$ measurement also shows much more structure in both the real and imaginary parts than the current HITRAN data. The peaks at $\sim 1625 \mathrm{~cm}^{-1}$, $\sim 2000 \mathrm{~cm}^{-1}$ and $\sim 3430 \mathrm{~cm}^{-1}$ are all attributable to water, and the increased resolution of the new measurements compared to that of the original Volz (1972) measurements allows the structure of the peaks to be better defined. However, the scattering of data points around $\sim 1625 \mathrm{~cm}^{-1}$ in the new data indicates remnants of water lines that may provide an additional source of error. Therefore more work is necessary to improve the method of eliminating gas lines. The amplitude of these water peaks is much greater in the new measurements than in the HITRAN data. Also the large O-H stretch feature at $\sim 3330 \mathrm{~cm}^{-1}$ in the HITRAN data is centred at the slightly higher wavelength of $\sim 3430 \mathrm{~cm}^{-1}$, although the positions of the remaining peaks remain unchanged between the two data sets. Currently the O-H stretch feature is modelled using a number of overlapping bands. This is due to limitations of the CDHO model that require absorption bands to be symmetric. However, it is anticipated that further work on the model may include an asymmetry parameter to better model this feature.

The differences between the new measurements and the current data are attributed to the inaccuracy of the volume weighting model used to calculate the refractive indices in the HITRAN data. The possible presence of water and the apparent inconsistencies between the real and imaginary parts of this refractive index data is also a source of error. The retrievals of water lines from the new measurements of dry sea salt aerosol indicate a relative humidity value of $0.4 \%$,

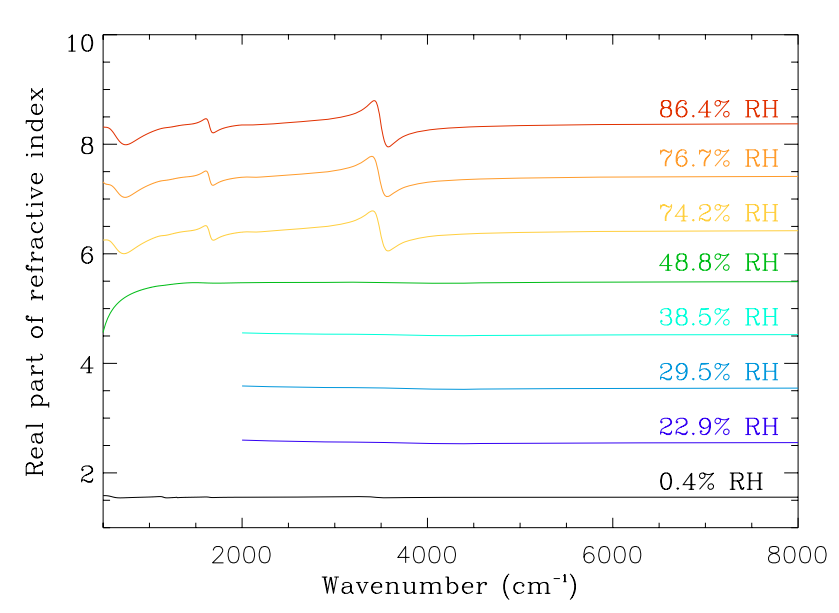

Fig. 6a. Variation of the real part of the measured refractive index, $m$ with relative humidity. The $0.4 \% \mathrm{RH}$ data are shown at the correct scale. Successive plots are displaced vertically by +1 unit each time.

which is assumed to be negligible for this analysis as minimal water features are observed in the retrieved refractive index spectrum.

\subsection{Variation with increasing relative humidity}

At high wavenumbers, the real part of the refractive index for sea salt aerosol tends towards a constant value (Figs. 3, 4 and 5). As the water content of the aerosol increases, this value decreases (Figs. 4 and 5). This is to be expected as more water is present in the aerosol and so its refractive index should become closer to that of water $(1.33$ at $500 \mathrm{~nm})$. This is particularly noticeable in the variation of the refractive index at $500 \mathrm{~nm}\left(m_{500}\right)$ shown in Fig. 1.

Figure $6 a$ to $b$ show the retrieved refractive index spectra for sea salt aerosol at various different RH values. For the three data sets at $22.9,29.5$ and $38.5 \% \mathrm{RH}$, no refractive index data is shown below $2000 \mathrm{~cm}^{-1}$ due to a low absorption signal in the measurements in this region. It can be seen that, in the real part of the refractive index, the size of the O-H stretch feature at $\sim 3430 \mathrm{~cm}^{-1}$ increases with $\mathrm{RH}$, as does the size of the peak at $\sim 1625 \mathrm{~cm}^{-1}$. The imaginary part of the refractive index exhibits similar trends. The peak due to the $\mathrm{O}-\mathrm{H}$ stretch from water at $\sim 3430 \mathrm{~cm}^{-1}$ grows significantly larger in amplitude as the RH increases, as does the peak at $\sim 1625 \mathrm{~cm}^{-1}$. This is consistent with the data from Weis and Ewing (1999) which showed similar trends in the $\mathrm{O}-\mathrm{H}$ stretch regions for aqueous $\mathrm{NaCl}$ spectra with increasing RH. However, the peak at $\sim 1330 \mathrm{~cm}^{-1}$ has disappeared in the spectrum at $48.8 \% \mathrm{RH}$, suggesting that it is due to the sea salt rather than water. The trough at $\sim 800 \mathrm{~cm}^{-1}$ in the real part of the data becomes deeper and more defined as the $\mathrm{RH}$ increases and the peak at $\sim 400 \mathrm{~cm}^{-1}$ begins to appear. 


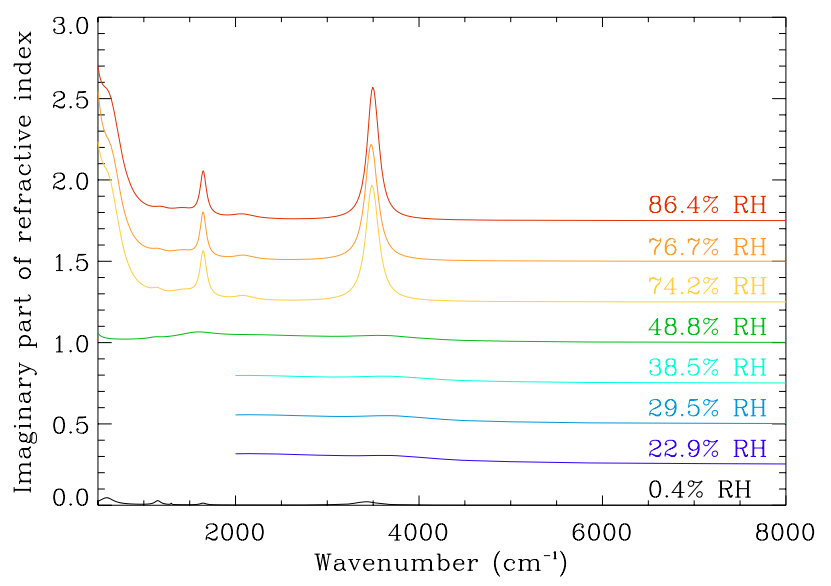

Fig. 6b. Variation of the imaginary part of the measured refractive index, $k$ with relative humidity. The $0.4 \% \mathrm{RH}$ data are shown at the correct scale. Successive plots are vertically displaced by +0.25 units each time.

\subsection{Volume mixing rules}

The calculations performed by Shettle and Fenn (1979) used sea salt data from Volz (1972) and water refractive indices from Hale and Querry (1973). Further and more comprehensive measurements have been made of the refractive indices of water, most recently by Segelstein (1981). To confirm that the discrepancy between the new measurements and the refractive indices calculated by Shettle and Fenn (1979) are not merely due to inaccurate data for water, the volume mixing calculations are repeated here using the new measurements of dry sea salt aerosol, and the Segelstein (1981) data for the refractive indices of water. The refractive index spectrum for $74 \% \mathrm{RH}$ sea salt aerosol was calculated using the volume weighting formula (following Shettle and Fenn, 1979):

$n=n_{w}+\left(n_{0}+n_{w}\right)\left[\frac{r_{0}}{r\left(a_{w}\right)}\right]$

where $n_{0}$ is the refractive index of dry sea salt aerosol, $n_{w}$ is the refractive index of water, $r_{0}$ is the dry aerosol particle size and $r\left(a_{w}\right)$ is the size of the wet sea salt aerosol for which the refractive index is required. The calculated refractive indices are compared with the new measurements in Fig. 7. It is clear that, while the positions and shapes of the peaks are similar, the two refractive index spectra are sufficiently different that it may be assumed that the volume mixing rules used to calculate refractive index for wet aerosols provide an inaccurate result compared to direct measurements. This is expected as the dissociation of salt ions upon dissolution of the salt means that the resulting solution cannot merely be considered as a mixture of whole salt particles and water.
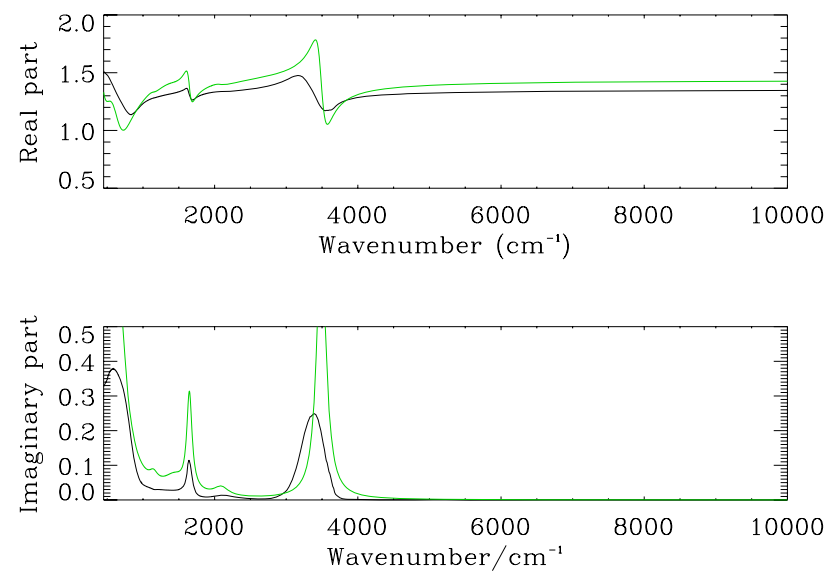

Fig. 7. Refractive index spectra of $70 \%$ RH SSA from new, direct measurements (green), and calculated from the volume mixing rules using the newly measured dry SSA refractive index (black). The real part of the refractive index is shown in the top plot, and the imaginary part in the bottom plot.

\section{Conclusions}

The refractive indices of sea salt aerosol have been obtained for a range of relative humidity values. A single set of measurements was previously made by Volz (1972). In these measurements the real and imaginary parts of the refractive index were derived by two different measurements: the real part using transmission measurements and the imaginary part using reflectance measurements, both from dry, bulk samples. We found that the real and imaginary parts of the refractive indices from these measurements did not correspond according to the CDHO model, and therefore did not follow the Kramers-Kronig relationship.

The refractive indices for wet sea salt aerosols were previously calculated using a volume weighting formula by Shettle and Fenn (1979). The calculations were performed using refractive index data for sea salt from Volz (1972). The refractive index data for water used in the calculations were from Hale and Querry (1973) and have since been superceded by water measurements from Segelstein (1981), among others. Further calculations were performed using the new refractive index data for sea salt presented in this paper and more recent data for the refractive indices of water from Segelstein (1981). The resulting refractive indices of wet SSA are different to direct measurements of SSA at the same RH. This suggests that the volume mixing rules are inadequate for describing the refractive indices of solutions.

The results presented here have been retrieved from direct measurements of aerosols and are at a higher resolution than previous data. This means that the infra-red scattering and absorption of sea salt aerosols can now be more accurately predicted, and more precise parameters may be used 
in atmospheric models. Possible further work may involve improving the retrieval of gas lines from transmission spectra to improve accuracy in the spectral regions where water is expected, as well as extending the CDHO method to allow for the presence of asymmetry in the absorption bands.

Acknowledgements. Thanks are due to A. Clack, D. Constable, A. Dudhia, J. Perry, P. Read, J. Temple and R. G. Williams for their invaluable generosity with their time and skills. Many thanks also to NERC for providing funding for the project and to the RAL MSF for the use of their spectroscopy facility. Finally, thanks to A. Lambert for additional comments provided during the writing of this paper.

Edited by: A. Lambert

\section{References}

Blackford, D. B. and Simons, G. R.: Particle Size Analysis of Carbon Black, Particle Characterization, 4, 112-117, 1986.

Clapp, M. L., Miller, R. E., and Worsnop, D. R.: Frequencydependent optical-constants of water ice obtained directly from aerosol extinction spectra, J. Phys. Chem., 99, 6317-6326, 1995.

Culkin, F.: The major constituents of sea water, in: Chemical Oceanography, edited by: Riley, J. P. and Skirrow, G., 1, 121161, Academic Press, first edn., 1965.

Cziczo, D. J. and Abbatt, J. P. D.: Infrared observations of the response of $\mathrm{NaCl}, \mathrm{MgCl}_{2}, \mathrm{NH}_{4} \mathrm{HSO}_{4}$, and $\mathrm{NH}_{4} \mathrm{NO}_{3}$ Aerosols to changes in relative humidity from 298 to $238 \mathrm{~K}$, J. Phys. Chem. A., 104, 2038-2047, 2000.

Cziczo, D. J., Nowak, J. B., Hu, J. H., and Abbatt, J. P. D.: Infrared spectroscopy of model tropospheric aerosols as a function of relative humidity: observations of deliquescence and crystallization, J. Geophys. Res. 102, 18 843-18 850, 1997.

Dobbie, J. S., Li, J., Harvey, R., and Chylek, P.: Sea-salt optical properties and GCM forcing at solar wavelengths, Atmos. Res., 65, 211-233, 2003.

DOE: Handbook of methods for the analysis of the various parameters of the carbon dioxide system in sea water,version 2 , oRNL/CDIAC-74, 1994.

Dorsey, N. E.: Properties of ordianary water-substance in all its phases: water vapor, water and all the ices, Reinhold Publishing Corp., New York, 1940.

Dubovik, O., Holben, B., Eck, T. F., Smirnov, A., Kaufman, Y. J., King, M. D., Tanre, D., and Slutsker, I.: Variability of absorption and optical properties of key aerosol types observed in worldwide locations, J. Atmos. Sci., 59, 590-608, 2002.

Finlayson-Pitts, B. J. and Hemminger, J. C.: Physical chemistry of airborne sea salt particles and their components, J. Phys. Chem. A, 104, 11 463-11 477, 2000.

Grainger, R. G., Lucas, J., Thomas, G. E., and Ewen, G. B. L.: Calculation of Mie derivatives, Appl. Optics, 43, 5386-5393, 2004.

Hale, G. M. and Querry, M. R.: Optical properties of water in the near infrared, Appl. Optics, 12, 564-568, 1973.

Hess, M., Koepke, P., and Schult, I.: Optical Properties of Aerosols and Clouds: The software package OPAC, Bull. Am. Meteorol. Soc., 79, 831-844, 1998.

IPCC: The Physical Basis of Climate Change, http://ipcc-wg1.ucar. edu/wg1/wg1-report.html, 2007.
Kalman, R. E.: A New Approach to Linear Filtering and Prediction Problems, J. Basic Eng., 82, 35, 1960.

King, M. D., Kaufman, Y. J., Tanre, D., and Nakajima, T.: Remote sensing of tropospheric aerosols from space: past, present and future, Bull. Am. Meteorol. Soc., 80, 2229-2259, 1999.

Lewis, E. R. and Schwartz, S. E.: Sea Salt Aerosol Production Mechanisms, Methods, Measurements, and Models, American Geophysical Union, 2004.

Li, J., Ma, X., von Salzen, K., and Dobbie, S.: Parameterization of sea-salt optical properties and physics of the associated radiative forcing, Atmos. Chem. Phys., 8, 4787-4798, 2008, http://www.atmos-chem-phys.net/8/4787/2008/.

Lohmann, U. and Feichter, J.: Global indirect aerosol effects: a review, Atmos. Chem. Phys., 5, 715-737, 2005, http://www.atmos-chem-phys.net/5/715/2005/.

Maybeck, P. S.: Stochastic Models, Estimation and Control, vol. 1, Academic Press Inc., 1979.

Milham, M. E., Frickel, R. H., Embury, J. F., and Anderson, D. H.: Determination of optical-constants from extinction measurements, J. Opt. Soc. Am., 71, 1099-1106, 1981.

Murphy, D. M., Anderson, J. R., Quinn, P. K., McInnes, L. M., Brechtel, F. J., Kreidenweis, S. M., Middlebrook, A. M., Posfai, M., Thomson, D. S., and Buseck, P. R.: Influence of sea-salt on aerosol radiative properties in the Southern Ocean marine boundary layer, Nature, 392, 62-65, 1998.

Neto, R. B. S., de Mendoca, J. P. R. F., and Lesche, B.: Determination of absolute values of refractive index of liquids using an interferometric method, Revista de Fisica Aplicada e Instrumentacao, 17(2), 74-79, 2004.

Penner, J. E., Andreae, M., Annegarn, H., Barrie, L., Feichter, J. F., Hegg, D., Jayaraman, A., Leaitch, R., Murphy, D., Nganga, J., and Pitari, G.: Aerosols, their direct and indirect effects, in: Climate Change 2001: The Scientific Basis. Contribution of Working Group I to the Third Assessment Report of the Intergovernmental Panel on Climate Change, edited by: Houghton, J. T., Ding, Y., Griggs, D. J., Noguer, M., van der Linden, P. J., Dai, X., Maskell, K., and Johnson, C. A., 1, 289-348, Cambridge University Press, first edn., 2001.

Querry, M. R., Holland, W. E., and Waring, R. C.: Complex refractive index in the infrared for $\mathrm{NaCl}, \mathrm{NaNO} 3$ and $\mathrm{NaHCO} 3$ in water, J. Opt. Soc. Am., 66, 830-836, 1976.

Rodgers, C. D.: Inverse Methods for Atmospheric Sounding: Theory and Practice, vol. Series on Atmospheric, Oceanic and Planetary Physics - Vol. 2, World Scientific Publishing Co. Pte. Ltd., 2000.

Rothman, L. S.: The HITRAN 2004 molecular spectroscopic database, Journal of Quantitative Spectroscopy and Radiative Transfer, 96, 139-204, 2005.

Savoie, D. L. and Prospero, J. M.: Particle size distribution of nitrate and sulfate in the marine atmosphere, Geophys. Res. Lett., 9, 1207-1210, 1982.

Segelstein, D. J.: The complex refractive index of water, Master's thesis, University of Missouri - Kansas City, 1981.

Shettle, E. P. and Fenn, R. W.: Models for the aerosols of the lower atmosphere and the effects of humidity variations on their optical properties, AFGL-TR-79-0214, 1979.

Tang, I. N. and Munkelwitz, H. R.: Simultaneous determination of refractive index and density of an evaporating aqueous solution droplet, Aerosol. Sci. Tech., 15, 201-207, 1991. 
Tang, I. N., Tridico, A. C., and Fung, K. H.: Thermodynamic and optical properties of sea salt aerosols, J. Geophys. Res., 102, 23 269-23 275, 1997.

Thomas, G. E., Bass, S. F., Grainger, R. G., and Lambert, A.: Retrieval of aerosol refractive index from extinction spectra using a damped oscillator band model, Appl. Optics, 44, 1332-1341, 2004.

Torres, O., Bhartia, P. K., Herman, J. R., Ahmad, Z., and Gleason, J.: Derivation of aerosol properties from satellite measurements of backscattered ultraviolet radiation - Theoretical basis, J. Geophys. Res., 103(D14), 17 099-17 110, 1998.

Twomey, S. and McMaster, K. N.: The production of condensation nuclei by crystallizing salt particles, Tellus, 7, 458-461, 1955.

Volz, F. E.: Infrared refractive index of atmospheric aerosol substances, Appl. Optics, 11, 755-759, 1972.
Weis, D. D. and Ewing, G. E.: Water content and morphology of sodium chloride particles, J. Geophys. Res., 104, 21275-21285, 1999.

Wilson, T. R. S.: Salinity and the major elements of sea water, in: Chemical Oceanography, edited by: Riley, J. P. and Skirrow, G., 1, 365-413, Academic Press, second edn., 1975.

Winter, B. and Chylek, P.: Contribution of sea salt aerosol to the planetary clear-sky albedo, Tellus, 49B, 72-79, 1997.

Yunus, W. M. M.: Temperature dependence of refractive index and absorption of $\mathrm{NaCl}, \mathrm{MgCl} 2$, and $\mathrm{NaSO} 4$ solutions as major components in natural seawater, Appl. Optics, 31, 2963-2964, 1992. 